\title{
Assessment of Indoor Environmental Quality in schools by combining survey and modelling: a case study in Albania
}

\author{
Francesco Salamone ${ }^{1, *}$, Lorenzo Belussi ${ }^{1}$, Ludovico Danza ${ }^{1}$, Matteo Ghellere ${ }^{1}$, Italo \\ Meroni $^{1}$, Arben Shtylla ${ }^{2}$,Etleva Dobjani' ${ }^{2}$ and Saimir Shtylla ${ }^{2}$ \\ ${ }^{1}$ ITC-CNR, via Lombardia 49, 20098 San Giuliano Milanese (Mi), Italy \\ ${ }^{2}$ Polis University, Department of Applied Research, Rr. Bylis 12, Autostrada Tiranë-Durrës, Km 5, \\ 1051, Tirana, Albania
}

\begin{abstract}
The article describes the outcomes of the monitoring campaign carried out in an educational building nearby Tirana, capital of Albania. Performed under the bilateral agreement between the National Research Council of Italy and the Ministry of Education and Sport of the Republic of Albania, the study proposes a combined approach for the assessment of the IEQ, not limiting only in the collection of objective data through the environmental monitoring of indoor variables but it also includes the subjective perception of indoor environment by the students through the compilation of a specific questionnaire. The classrooms were also modelled using a parametric model combining the functionalities of Honeybee plugin with OpenStudio and Radiance. The results are illustrated by maps of the indoor microclimate and illuminance with spatial resolution of 0.5 meters and one-hour temporal resolution step. Aggregated index and environmental data derived from models are compared to those monitored with nEMoS. This hybrid method overcomes the drawback caused by a low resolution of the monitoring steps and allows the comparison of the objective and subjective perception of the considered environmental factors, as well as the identification of discrepancies in terms of objective evidence and subjective perception related to the considered environmental factors.
\end{abstract}

\section{Introduction}

The Indoor Environmental Quality (IEQ) is today fundamental to guarantee safety, wellbeing, health of building occupants and their productivity as well. In schools, children spend about $30 \%$ of their daily-time and adequate IEQ levels are mandatory to guarantee their health and performance. However, over the years several studies all over the world have emphasized how the indoor quality in schools is far from the mandatory levels. In 2007, in a large campaign carried out in several Finnish schools combining on-site monitoring with questionnaires revealed that poor air quality was the main cause of

* Corresponding author: $\underline{\text { salamone@ } @ \text { itc.cnr.it }}$ 
discomfort detected in all samples [1]. The survey also identified a series of diseases affecting the pupils even if there was not a strong statistical correlation with indoor quality. In spring 2017, [2] obtained similar results with a survey carried out in 21 Dutch schools, where the major cause of discomfort was again poor air quality. In Portuguese schools, [3] found that Indoor Air Quality (IAQ) parameters were not being fulfilled, with $\mathrm{CO} 2$ concentrations exceeding national and international limits. The results of the objective measurements made by [4] revealed low levels of IAQ and light in conventional schools. However, the same trend was noted also in high-performance buildings, with poor IAQ levels as in the conventional ones [5]. Low IEQ levels in educational buildings directly affect pupils' performance in learning. In [6] and [7], a strong correlation emerged between learning performance with environmental parameters, such as indoor temperature and ventilation rate. When pupils are involved in the IEQ evaluation in schools, a set of precautions related to building characteristics and individuals are required [8], [9]. The use of Internet of Thing-based (IoT) smart devices for monitoring the environmental variables and managing the indoor conditions is widely used for IEQ analysis [10], [11]. In this article, the IoT-based device nEMoS is used for the evaluation of the IEQ in two classrooms in an educational building in Tirana, Albania. To the authors' knowledge, few studies have been carried out in Albanian schools and have focused separately on one specific IEQ parameter at a time [12], [13]. The current research considers the most influential aspects of indoor environmental comfort (thermal, lighting and IAQ) as reported by the above-mentioned literature, carrying out a monitoring campaign and a modelling activity and analysing the perception of pupils during school time, in intermediate season.

\section{Case studies and Methodology}

The main goal of the research is the evaluation of the main aspects of IEQ in two classrooms in the "Kolë Jakova" school in Albania using two smart devices developed with the Do It Yourself (DIY) philosophy and a survey to evaluate pupils' perceptions within the indoor environment. Located in the North-Western suburb area of Tirana (Lat. 41 $21^{\prime} 28^{\prime \prime}$ N, Long. $19^{\circ} 45^{\prime} 44^{\prime \prime}$ E), the school building was built in $1983^{\dagger}$ and it is among the standard school building typologies during Socialist system (1945-90) in the country also known as "Shkolla tip"". Referring to National Technical Archive (NTA) it was originally designed for rural areas with a capacity of 12 classrooms ${ }^{\S}$. Nowadays, this capacity is a limiting factor that constrains the split of the didactic activity for some classes in the morning and for others in the afternoon. The school hosts 420 pupils for a total of 18 classrooms of the elementary and lower secondary cycle. The two classrooms chosen for the campaign are positioned on the opposite sides to consider the exposure's impact (Figure 1). In comparison to the original design, the building underwent to partial renovations such as the insulation of roof with waterproof layer on top (U-value $\left.=0.48 \mathrm{~W} / \mathrm{m}^{2} \mathrm{~K}\right)$ and the installation of heating system, a centralized two-stage plant with power ranging between $178-391 \mathrm{~kW}$ with radiators in each classroom. The external load-bearing masonry walls are uninsulated $\left(\mathrm{U}\right.$-value $\left.=1.26 \mathrm{~W} / \mathrm{m}^{2} \mathrm{~K}\right)$ whereas the windows $(130 \times 160 \mathrm{~cm})$ are single-glazed with aluminium frame (U-value of $6.8 \mathrm{~W} / \mathrm{m}^{2} \mathrm{~K}$ and $\left.\mathrm{SHGC}=0.7\right)$. Regarding the production of Domestic Hot Water (DHW), it is ensured from two separate boilers. The monitoring

\footnotetext{
$\dagger$ Referring site plan file at the Central National Technical Archive: "Shkollë në fshatin Bregu i Lumit dt 10.05.1983" (School in the village of Bregu i Lumit dated 10.05.1983)

* [ALB] Standard Typologies of schools from 1-storey to 4-storey high for specific context (urban, sub-urban and rural).

$\S$ Technical name of the typological project at the Central National Technical Archive: "Shkollë 8vjeçare me 12 dhe 8 klasa 73.6" (8-year cycle school with 12 and 8 classrooms 73.6)
} 
campaign and the survey aiming the collection of subjective and objective data was carried out from November 16th-18th, 2020 in the middle fall/winter school session in Albania. Figure 2 reports the positions of the students and position of each monitoring unit. All the 21 students were asked to provide the parental consent to take part to the three-day campaign. The subjective data were collected from the pupils' perceptions expressed in the specific questionnaire regarding three IEQ parameters (Thermal Comfort, Visual Comfort and Indoor Air Quality perception) in the classroom during the didactic activity. For three consecutive days at one-hour intervals, between 1.00 p.m. to 3.00 p.m. the students had to express in the questionnaire their perceptions concerned with thermal, visual and IAQ. In the definition of the survey particular attention was paid to the differences between the participants (Figure 3) involved in the test and to the different scales of evaluation based on the UNI EN ISO 10551 and UNI EN ISO 15251. Table 1 reports aggregated data for each classroom, in terms of number of participants, average age, height weight and clothing insulation (Iclo) as resulting from the analysis of data acquired by survey. While the metabolic rate (Metst) was defined in accordance with the EN ISO 7730 as detailed later.

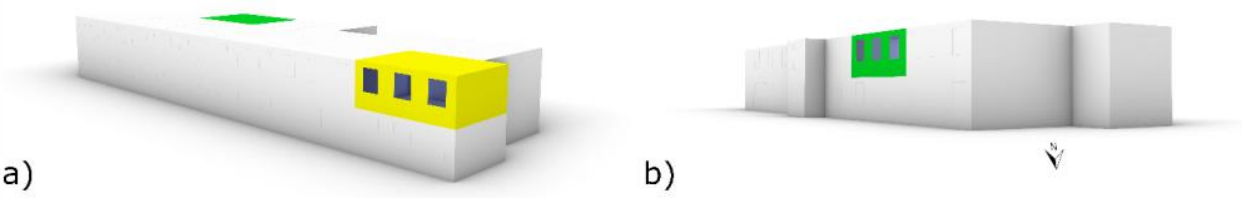

Fig. 1. 3D model of the school building and the chosen classrooms for monitoring campaign: a) in yellow class VIIIA; b) in green class IXB

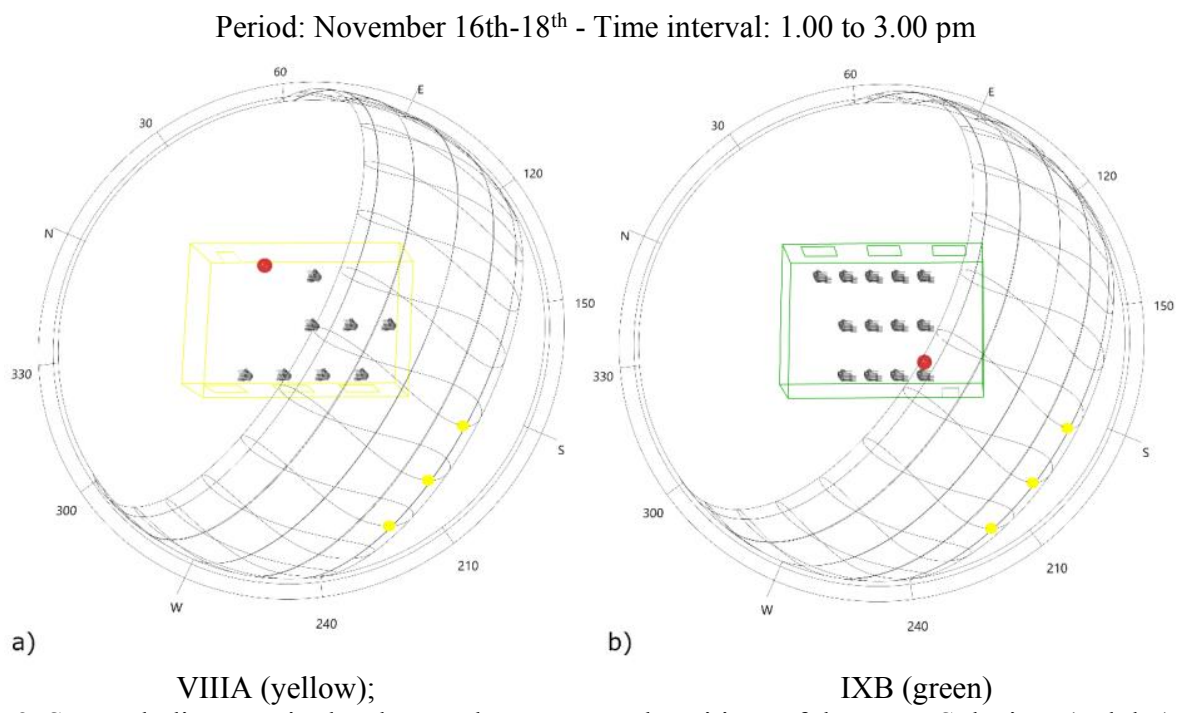

Fig. 2. Sun path diagrams in the chosen classrooms and positions of the nEMoS devices (red dot)

Table 1. Data of the 21 students involved in the study

\begin{tabular}{|c|c|c|c|c|c|c|}
\hline $\begin{array}{c}\text { Classroom } \\
\text { Color/N. }\end{array}$ & $\begin{array}{c}\text { Participants } \\
{[-]} \\
\text { Total(M-F) }\end{array}$ & $\begin{array}{c}\text { Age } \\
\text { [y] } \\
\text { Avg } \pm \text { std }\end{array}$ & $\begin{array}{c}\text { Weight } \\
\text { [kg] } \\
\text { Avg } \pm \text { std }\end{array}$ & $\begin{array}{c}\text { Height } \\
{[\mathbf{c m}]} \\
\text { Avg } \pm \text { std }\end{array}$ & $\begin{array}{c}\text { Iclo } \\
\text { [clo] } \\
\text { Avg } \pm \text { std }\end{array}$ & $\begin{array}{c}\text { Met } \text { st } \\
\text { [met] }\end{array}$ \\
\hline Green IXB & $13(6-7)$ & $14 \pm 0.5$ & $\begin{array}{c}57.92 \pm \\
14.38\end{array}$ & $\begin{array}{c}164.32 \pm 13 \\
.01\end{array}$ & $0.73 \pm 0.11$ & 1 \\
\hline Yellow IIIA & $8(4-4)$ & $13 \pm 0.5$ & $\begin{array}{c}50.42 \pm \\
6.42\end{array}$ & $\begin{array}{c}166.73 \pm \\
6.62\end{array}$ & $0.78 \pm 0.10$ & 1 \\
\hline
\end{tabular}


As illustrated in Figure 3, the questions on the thermal and visual perception are based on the five-point bipolar scale (from "cool" or "dark" = -2 to "warm" or "bright" $=+2$ ), while the questions about the IAQ perception is based on a unipolar scale (from "not smelly" $=0$ to "very smelly" $=3$ ). From the analysis of participants' answers it was also possible to calculate the thermal resistance of their clothing in compliance with Annex $\mathrm{C}$ of the Standard EN ISO 7730. An additional thermal resistance equal to 0.1 clo for sedentary activities due to the standard school chair was considered [14]. The standard metabolic rate Metst is defined in accordance with the value reported in Annex B of EN ISO 7730. The collection of the indoor environmental variables was carried out using nEMoS [14], [15]. The position of the monitoring units within the classrooms was dictated by practical needs (proximity to the power supply) and requests from school staff (not to position devices in the middle of the classrooms). Due to the limited time available for the campaign, the model was not calibrated even though the outdoor environmental data for the scheduled period exported from [16] have been considered. The simulation was performed using Ladybug, Honeybee and Butterfly, three of the four series of plugins of the family of Ladybug tools for Rhinoceros ${ }^{\circledR}$ software [17].

\begin{tabular}{|c|c|c|c|c|c|}
\hline \multicolumn{2}{|c|}{ 1. Please indicate your thermal perception (Mark with $\mathbf{X}$ only one alternative for each hour) } \\
\hline 13.00 & & & & & \\
\hline 14.00 & & & & & Slightly warm \\
\hline 15.00 & & & & \\
\hline
\end{tabular}

2. Please indicate your visual perception (Mark with $\mathbf{X}$ only one alternative for each hour)

\begin{tabular}{|c|c|c|c|c|}
\hline 13.00 & & & & \\
\hline 14.00 & & & & \\
\hline 15.00 & & & & \\
\hline
\end{tabular}

3. Please indicate your air quality perception (Mark with $\mathbf{X}$ only one alternative for each hour)

\begin{tabular}{|c|c|c|c|c|}
\hline \multirow{2}{*}{\multicolumn{5}{|c|}{13.00}} \\
\hline & & & & \\
\hline \multicolumn{5}{|l|}{14.00} \\
\hline 15.00 & & & & \\
\hline
\end{tabular}

Fig. 3. Structure of questionnaire for IEQ perception (translated from Albanian) 
The model used for the assessment of the thermal comfort [18] on each classroom is displayed in Figure 4.
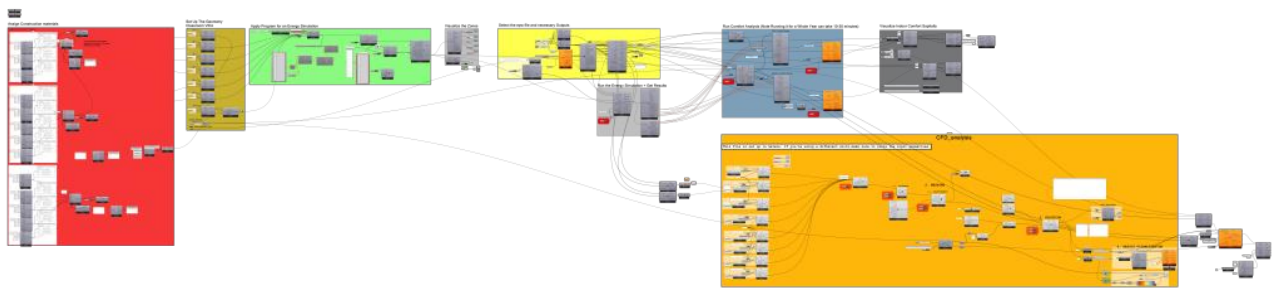

Fig. 4. Flowchart for modelling indoor thermal comfort

On the left, in the red box, all the layers composing each opaque envelope element are defined considering: thickness in $[\mathrm{m}]$, conductivity $[\mathrm{W} / \mathrm{mK}]$, density $\left[\mathrm{kg} / \mathrm{m}^{3}\right]$ and specific heat $[\mathrm{J} / \mathrm{kgK}]$ of the material. For windows, the U-value $\left[\mathrm{W} / \mathrm{m}^{2} \mathrm{~K}\right]$, the SHGC and the Visible Transmittance were defined, too. In the brown box are included the components identifying the geometric characteristics of the classroom. The green box is used to apply a program for an energy simulation. In this specific case, only the natural ventilation provided from windows' opening was considered, characterized by the fraction of the windows that are opened at each hour. Two different scenarios are considered: 1) closed windows; 2) open windows and CFD analysis performed using Butterfly and Open Foam plugins. The yellow box is used for the definition of the EnergyPlus weather file (.epw) and to select the specific type of simulation outputs such as zoneComfortMetrics, comfortMapVariables, surfaceTempAnalysis.

The output of the analysis performed with OpenStudio, is afterwards connected to the Honeybee_PMV Comfort Analysis Recipe tool (blue box) that allows to define the spatial distribution of the PMV considering the output of the model and the view factors in the selected geometries. The orange area is populated by the components used for the CFD analysis, thus allowing to visualize the distribution of the thermal comfort, in the case when windows and the door are opened. In this case, the geometries and meshing were modelled in Butterfly to define the OpenFoam case. Butterfly allows to perform the heat transfer analysis thought buoyantBoussinesqSimpleFoam solver. The results of the CFD analysis were confirmed by the convergence of residuals.

The model used for illuminance analysis [19] was performed with Ladybug and Honeybee plugins and combined with Radiance (Figure 5).

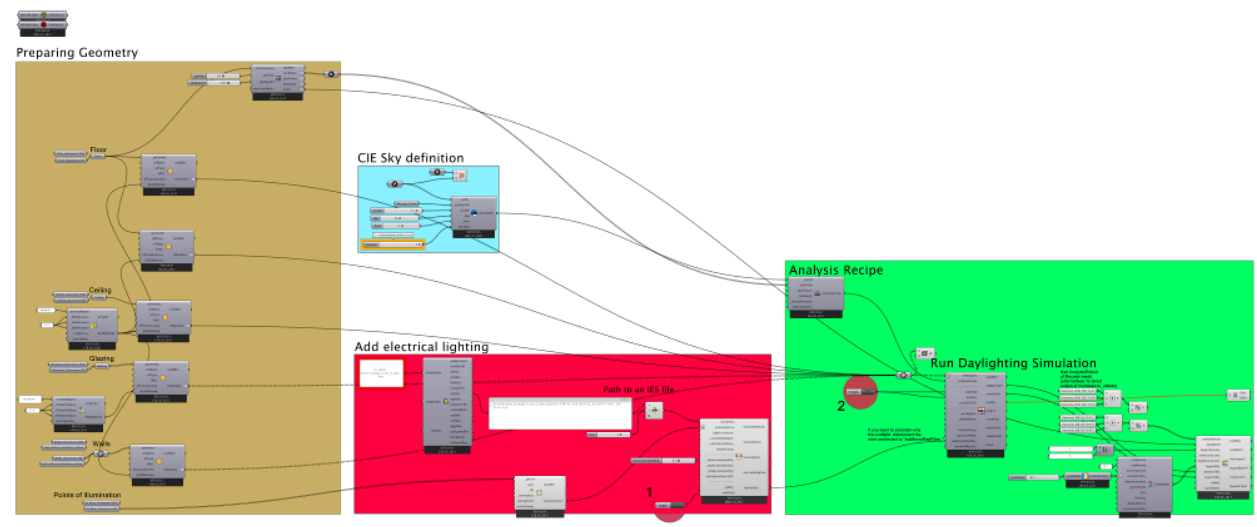

Fig. 5. Flowchart for modelling indoor illuminance assessment 
Starting from the definition of the geometry (brown box), in the middle, there are set the characteristics of the sky (cyan) and the electrical lighting (red). Considering the period of monitoring phase, we opted for an intermediate sky without sun [20] as defined by the International Commission on Illumination (CIE) [21] and reported in the ISO 15469:2004 normative. The artificial lighting devices of the classrooms consisted in six Spiral Compact Fluorescent Bulb (Spiral CFL) with a nominal power of $40 \mathrm{~W}$ and a Correlated Colour Temperature (CCT) of $6700 \mathrm{~K}$. Lights were considered on during class time. In the green box on the right, it is possible export geometries and all other information to .rad files and run combined daylighting and lighting analysis using Radiance.

$\mathrm{PMV}$ and illuminance values modelling were performed over a $50 \times 50 \mathrm{~cm}$ point grid placed $0.75 \mathrm{~m}$ above floor level in accordance with the height of school desk ad indicated by UNI EN 1729-1:2016 and confirmed by inspection.

No model was used to simulate the distribution of the $\mathrm{CO}_{2}$ concentration in the two classrooms.

\section{Results and discussions}

Initially, the presented methodological approach allows to obtain results from modelling and subsequently compare them with data collected by nEMoS devices and users' feedback analysis. For the thermal modelling purposes, it was defined a model configuration for each ventilation scenario.

In the first one (closed windows), PMV mapping was performed considering the air temperature and relative humidity $(\mathrm{RH})$ derived from the OpenStudio simulation, the radiant temperature (RT) was defined considering the OpenStudio output of indoor surface temperatures and view factors for each of the considered test point. Metabolic rate (MR) and thermal resistance of clothing (CLO) are the mean values provided by students.

In the second scenario (opened windows), a combined CFD and OpenStudio model was defined. In this case the environmental variables were considered as follows: RH and RT as resulting from the OpenStudio output; air temperature and air velocity as resulting from the CFD model. Both MR and CLO were derived from the survey responses analysis as an average value. Outdoor environmental parameters are derived from data acquired in the city of Tirana for the considered monitoring period [14]. The illuminance maps were defined in accordance with Radiance model as described above (Figure 5).

Figure 6 reports the maps of the simulation in terms of PMV and illuminance values.

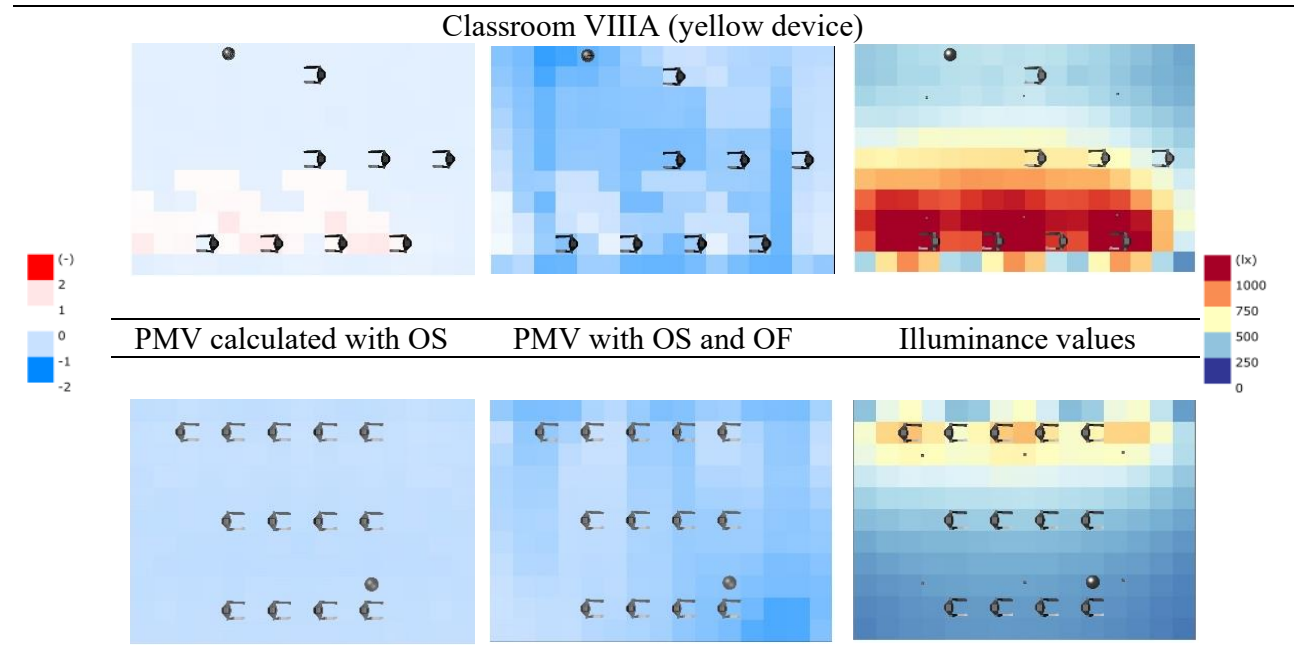


Classroom IXB (green device)

Fig. 6. Simulation mapping of the two classrooms

It is possible to compare the PMV indicators and Illuminance levels retrieved from models (considering the positions of students in the two classrooms) with those derived from data acquired thought monitoring of indoor environmental variables of the two positions in the selected classrooms (Figure 7).
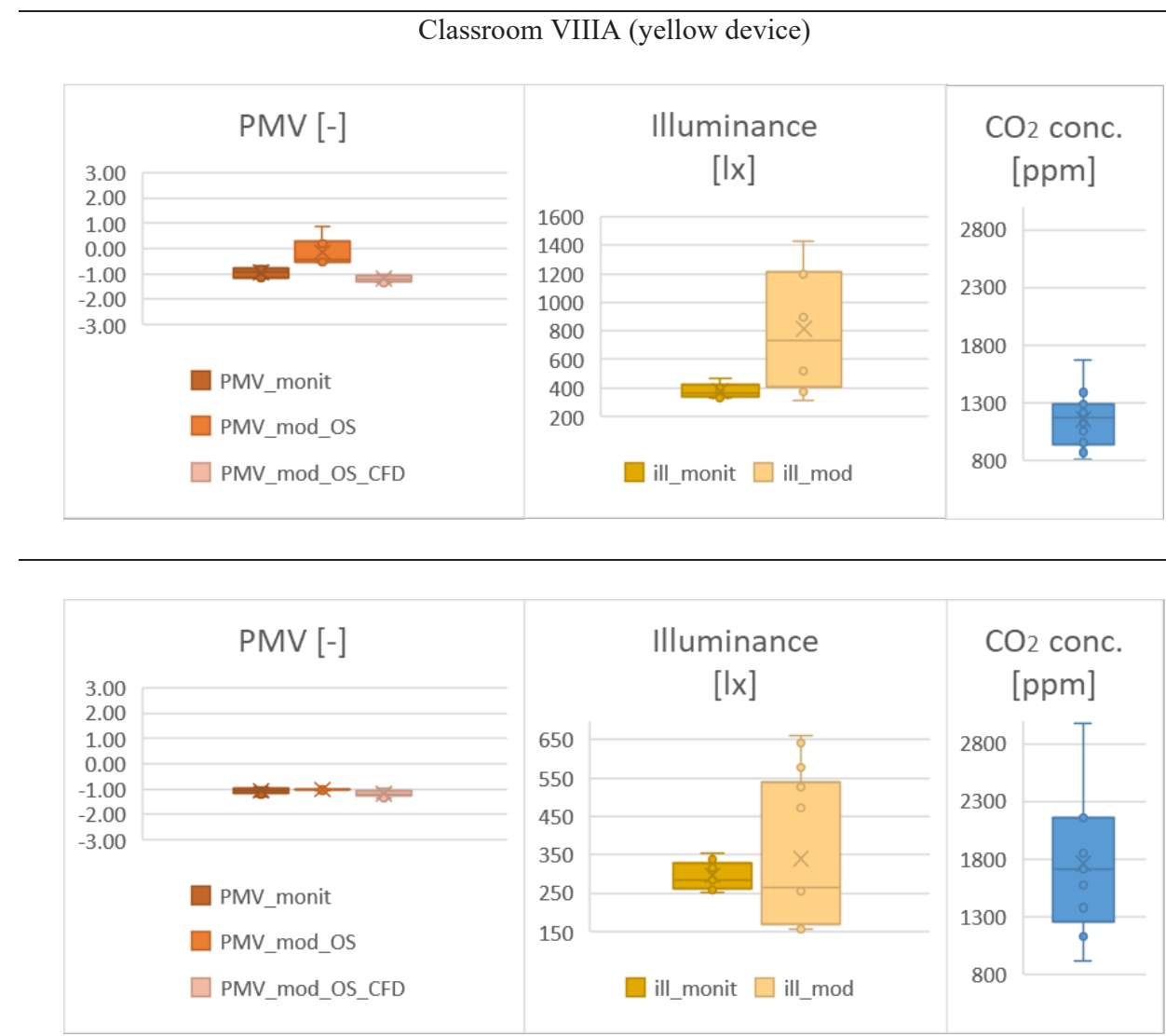

Classroom IXB (green device)

Fig. 7. Data monitored (monit) and modelled (mod)

The comparison of PMV values highlights similar results between modelling and monitoring data (Figure 7). In class VIIIA, OpenStudio plus CFD modelling produces closer PMV values than the simple OpenStudio model. On the other hand, the comparison of Illuminance values shows a limited convergence of results respect to monitored data. Unlike the modelled ones, real illuminance values have a limited fluctuation over the time, because only one measuring point was considered, far from the windows. The average modelled illuminance value of IXB is closer to that monitored.

Finally, Figure 8 reports the data of Thermal Comfort (TC), Visual Comfort (VC) and IAQ as perceived by students. 
Classroom VIIIA (yellow device)
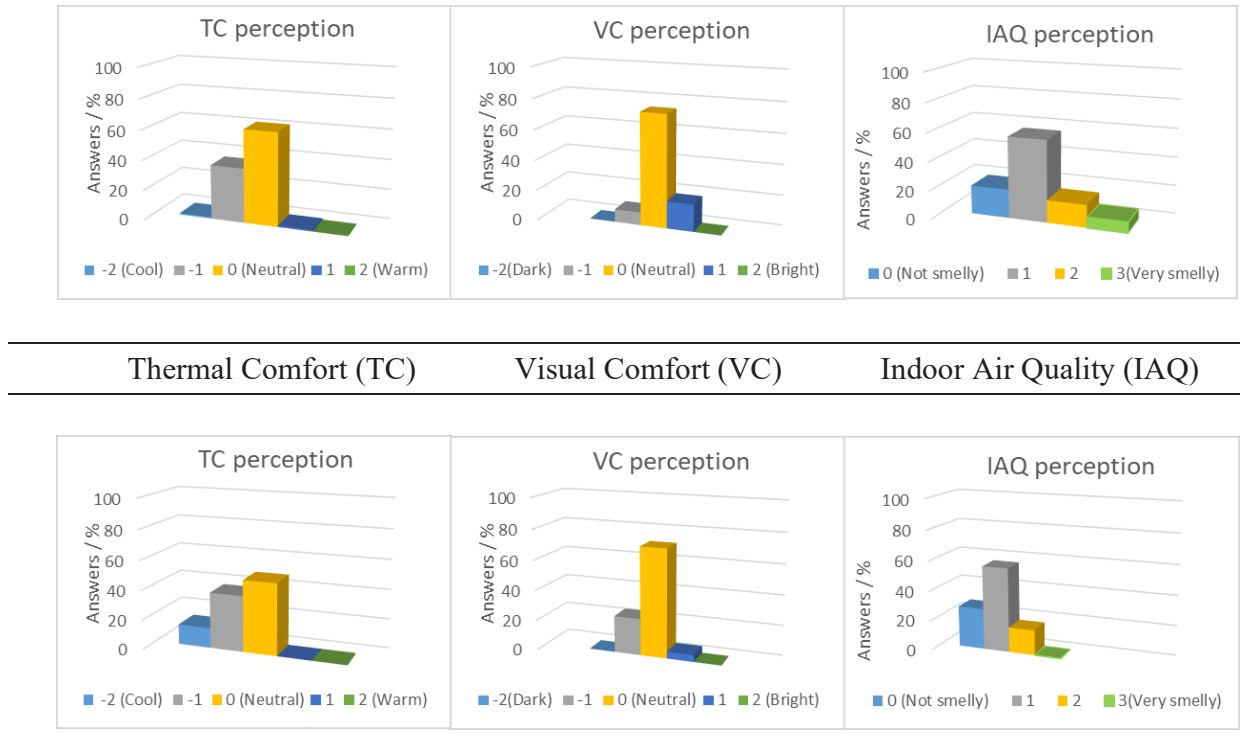

Classroom IXB (green device)

Fig. 8. Subjective perception responses in the two classrooms

The analysis of TC shows a higher neutral perception of students in IXB classroom in comparison to the VIIIA classroom $(62 \%$ vs $48 \%)$ and a lower "- 2 - Cool" perception $(0 \%$ vs $14 \%$ ). In the analysis of $\mathrm{VC}, 74 \%$ and $71 \%$ of the students respectively of the IXB and VIIIA classrooms, neutral perception was the most common. In IXB classroom the percentage of pupils that felt the "slightly bright" condition resulted more than three time higher than in the VIIIA classroom (18\% and 5\% respectively). At the opposite, the "slightly dark" perception is three time higher in VIIIA than XIB (24\% and $8 \%$ respectively).

Finally, the results regarding the IAQ perceptions partially reflect the analysis of the corresponding monitored data $\left(\mathrm{CO}_{2}\right)$. Despite a consistent difference in the $\mathrm{CO}_{2}$ concentration values (in the IXB value is $600 \mathrm{ppm}$ higher than in the VIIIA classroom), only $7 \%$ of the students in the IXB classroom perceive the air as "very smelly", while the most common perception in both classrooms is "1 - low smelly". Probably, it may be related to the low sensitivity of students to air quality, considering that the other IEQ aspects are more immediate to assess (i.e. room brightness, temperature level).

\section{Conclusions}

Before discussing the final conclusions, it is appropriate to remind two important limitations of the monitoring campaign and survey. First, it was performed in an unusual period because of the ongoing pandemic situation worldwide constraining the presence of 
about half of the total number of students during the didactic activity. Another important limitation of the study is related to the duration of the monitoring campaign: only three days that are not enough to perform the calibration and validation of the models. Nevertheless, the monitoring of environmental parameters into two classrooms placed on opposite sides of the buildings allowed to comprehend the main differences concerned with the environmental variables (or index) distribution to define an optimized monitoring campaign in terms of points of measurement. In particular, it is possible to highlight that the spatial variability of PMV is not underestimated during the monitoring campaign considering only one point.

Regarding the visual aspects, the situation is different. The use of only one point for the monitoring of illuminance values, is not enough to consider the variability of illuminance especially in VIIIA classroom. The main difference among monitored data in the two classrooms regards the $\mathrm{CO}_{2}$ concentration, with the highest value encountered in the IXB classroom. The $\mathrm{CO}_{2}$ differences are not reflected by IAQ perception and this is probably due to students' adaptation to the environment [3].

Not less irrelevant is the fact that the monitoring campaign was performed relying on devices based on the principles of the DIY philosophy, using low-cost sensors and 3Dprinted techniques. Furthermore, it gained lot of attention from the students in both classrooms, with the expectation to grow further their interest towards a topic of growing interest such as (IoT) and their awareness about the importance of indoor comfort issues. In this perspective, it might be possible to bring students close to the themes of IEQ and technology.

The modelling confirmed the necessity to use more than one monitoring point, especially when visual aspects are considered. Measurement performed on a large scale, with devices such as nEMoS, along with feedback provided by a larger number of participants, will make it possible to identify differences between objective data and subjective perceptions related to the considered EFs, considering the target audience.

\section{Acknowledgement}

The authors thank the Ministry of Education and Sport of the Republic of Albania for the authorization to conduct the monitoring campaign. This project is financed by the Agency for Research, Technology and Innovation (ARTI) ${ }^{* *}$

\section{References}

1. M. Turunen, O. Toyinbo, T. Putus, A. Nevalainen, R. Shaughnessy, U. HaverinenShaughnessy, Int. J. Hyg. Environ. Health. 217, 733-739 (2014)

2. P.M. Bluyssen, D. Zhang, S. Kurvers, M. Overtoom, M. Ortiz-Sanchez, Build. Environ. 138 (2018)

3. L. Dias Pereira, L. Neto, H. Bernardo, M. Gameiro da Silva, Energy Res. Soc. Sci. 32, 23-43 (2017)

4. S. Vilcekova, L. Meciarova, E.K. Burdova, J. Katunska, D. Kosicanova, S. Doroudiani, Build. Environ. 120, 29-40 (2017)

5. E. Oldham, H. Kim, Atmos. 11, 81 (2020)

6. U. Haverinen-Shaughnessy, R.J. Shaughnessy, E.C. Cole, O. Toyinbo, D.J. Moschandreas, Build. Environ. 93, 35-40 (2015)

\footnotetext{
** [ALB] Ky projekt u mundësua falë financimit të Agjensisë Kombëtare të Kërkimit Shkencor dhe Inovacionit (AKKSHI)
} 
7. O. Toyinbo, R. Shaughnessy, M. Turunen, T. Putus, J. Metsämuuronen, J. Kurnitski, U. Haverinen-Shaughnessy, Build. Environ. 104, 114-121 (2016)

8. S.S. Korsavi, A. Montazami, Build. Environ. 153, 1-16 (2019)

9. E.C. Hameen, B. Ken-Opurum, Y.J. Son, Sustain. 12 (2020)..

10. G. Marques, R. Pitarma, Appl. Sci. 12(9), 3712 (2019).

11. G. Marques, R. Pitarma, J. Sens. Actuator Networks. 8(3), 43 (2019).

12. E. Keco, U. Pont, A. Mahdavi, Appl. Mech. Mater. 887, 484-491 (2019).

13. O. Hänninen, N. Canha, A. V. Kulinkina, I. Dume, A. Deliu, E. Mataj, A. Lusati, M. Krzyzanowski, A.I. Egorov, Air Qual. Atmos. Heal. 10, 773-782 (2017).

14. F. Salamone, L. Belussi, L. Danza, M. Ghellere, I. Meroni. Sensors 15(6), 1301213027 (2015).

15. F. Salamone, L. Danza, I. Meroni, M.C. Pollastro. Sensors 17(4), 828 (2017).

16. https://www.meteoblue.com/en/weather/week/tirana_albania_3183875 (assessed on 20/11/2020).

17. M. S. Roudsari, M. Pak, A. Smith, Proceedings of the 13th international IBPSA conference 3128-3135 (2013).

18. https://app.box.com/s/ska48ju3dmvfqycnljmix4r7u8kw88p6 (assessed on 07/07/2021)

19. https://app.box.com/s/fw10anc0vqy3uuo2vbisg3p71uaipj6o (assessed on 07/07/2021)

20. http://climate-baseddaylighting.com/lib/exe/fetch.php?media=resources:mardaljevic_chap5.pdf (assessed on $15 / 04 / 2021)$.

21. http://www.cie.co.at/publications/cie-standard-overcast-sky-and-clear-sky (assessed on 15/04/2021). 